\section{Student demand in Australia}

SIR-Tania Ewing (Nature 338, 191; 1989) makes the point of decreasing student demand in Australia for places in science courses and of disenchantment with career prospects for non-tenured postdoctoral scientists. Both observations are accurate, but the data used to support the former proposition are presented somewhat ambiguously.

Entry scores (out of 500) of 320 (1987) and 300 (1989) were quoted for the faculty of science of the University of Sydney while scores of 295 (1988) and 279 (1989) were given for the faculty of science of the University of Melbourne. It should be noted that the latter scores are out of a usual maximum of 410 . Furthermore, the faculty of science at the University of Melbourne has deliberately increased its student intake this year by approximately 10 per cent, and the lower cut-off score reflects this planned expansion.

In the United Kingdom (Nature 334, 393-394; 1988) and in Australia, science courses are progressively providing a broad framework for a wide range of career directions. It is this message that we are attempting to market to potential science students; unqualified interpretation of data will be counterproductive to such efforts.

T. W. HEALY

(Dean)

J. A. McKenzIE (Associate Dean, Students)

Faculty of Science,

University of Melbourne,

Parkville, Victoria 3052,

Australia

\section{Animal experiments}

SIR-We wonder how many of your readers were concerned over a report published earlier this year which in our view caused an unacceptable level of suffering in the experimental animals concerned.

The paper in question was "Maturation and connectivity of the visual cortex in monkey is altered by prenatal removal of retinal input" (Nature 337, 265-267; 1989). The study involved major surgery on two pregnant macaques (Macaca cynomolgus) to expose the fetal heads; the eyes of both fetuses removed; six weeks to two months later the blinded animals were prematurely delivered by caesarean section. The infants were bottle-fed and, although it was not stated, presumably removed from their mothers. They were subsequently subjected to craniotomy for tests on the visual cortical area and were then killed.

This fundamental research deprived two primates of their young and their young suffered the effects of maternal deprivation and loss of sight. Such gross interference with a highly intelligent species requires overwhelming justification - if it can ever be justified.

This work was performed in France and was therefore not subject to British law. We believe that such work would never be permitted in Great Britain under the Animals (Scientific Procedures) Act 1986. We therefore question the decision of Nature to permit publication of this work, even allowing for Nature's stated policy of publishing "what will be of the most scientific interest to our readers".

To my knowledge, no other reputable scientific journal published in this country will accept any reports of work which clearly would not have been authorized under British law.

\section{Committee for the Reform of}

Clive Hollands

Animal Experimentation,

10 Queensferry Street,

Edinburgh

EH2 4PG, UK

\section{Conference participation}

SIR-All scientists should have an equal right to participate in international scientific conferences but unfortunately this is not the case, for several reasons.

There are two categories of countries those with convertible currencies and those without them. Conference fees are rising more than inflation and they invariably have to be paid in US dollars or other convertible currencies.

This practice discriminates strongly against scientists from countries with no convertible currencies, and that is the larger and poorer part of the world. Western organizers of conferences forget too easily that for many of us - even when local funds are available - it is difficult if not impossible to obtain them in convertible form. They also forget that delivery of letters may take weeks rather than days in those countries and that the transfer of $\$ 10$ may be as hard a task as the transfer of $\$ 10,000$. I regularly receive conference circulars with requests for advance payments and with deadlines that are impossible to meet.

As a Hungarian scientist, I am under stress and feel miserable at being prevented from participating in important international conferences because of the convertible currency problem, and I am sure I am not alone in this respect. This situation will further widen the gap between the scientific achievements of developed and "not so developed" countries, which is in nobody's interest. Representatives of international scientific organizations such as COSPAR, IAU and
IUGG should seek a solution to this problem.

I should like to make the following suggestions to conference organizers:

(1) They should accept participation fees in local (non-convertible) currencies and use them on other occasions within that particular country. National scientific committees or representatives could take care of the account.

(2) They should set aside part of conference income to support the participation of scientists from countries without convertible currencies.

(3) If the conference is organized in such a country, the local organizers should be obliged to support scientists with convertible currency at other conferences.

(4) They should not be rigid about closing dates for advance payments and deposits but should deal with each case individually.

Such arrangements would make organizing a conference more complicated but they would allow a more balanced participation of scientists from East and West.

ISTVÁN FEJES

FÖMI Satellite Geodetic Observatory,

H-1373, Budapest, Pf. 546,

Hungary

\section{A cost of progress}

SIR-The evils properly associated with eugenics have caused us to forget that it did have a partly rational basis. Kondrashov ${ }^{1}$ and Grinde ${ }^{2}$ have remarked on the progressive increase in deleterious alleles to be expected as a result of advances in medicine and public health. This expectation has a distinguished history; Muller's classic paper ${ }^{3}$ putting forward the concept of genetic load has a mature (if not a comprehensive) discussion.

LEIGH M. VAN VALEN

Department of Ecology and Evolution,

University of Chicago,

915 East 57 Street,

Chicago, Illinois 60637, USA

1. Kondrashov, A.S. Nature 336, 435-440 (1988).
2. Grinde, B. Nature 338, $24(1989)$.

3. Muller, H.J. Am. J. hum. Genet. 2, 111-176 (1950).

\section{Attendant problem}

SIR-In his delightful review of the second edition of the Oxford English Dictionary (Nature 338, 385; 1989), Stephen Jay Gould discusses the word 'scientist'. He writes of 'attendees' at the meeting of the British Association in 1834 at which the word was first suggested. Has he not confused active and passive? Doesn't he mean 'attenders'? If 'attendee' exists, it presumably means someone attended, for example a monarch or a bride, not someone attending.

DAVIo A. PYKE

King's College Hospital,

Denmark Hill.

London SE5 9RS, UK 